\title{
The potential of ground gravity measurements to validate GRACE data
}

\author{
D. Crossley ${ }^{1}$, J. Hinderer ${ }^{2}$, M. Llubes ${ }^{3}$, and N. Florsch ${ }^{4}$ \\ ${ }^{1}$ Earth and Atmospheric Sciences, Saint Louis University, 3507 Laclede Ave., St. Louis, MO 63103, USA \\ ${ }^{2}$ Institut de Physique du Globe / EOST, 5 Rue Descartes, Strasbourg 67084, France \\ ${ }^{3}$ LEGOS/CMES/CNRS Toulouse, France \\ ${ }^{4}$ Department de Geophysique Appliquee, UMR 7619 Sisyphe, Paris, France
}

\begin{abstract}
New satellite missions are returning high precision, time-varying, satellite measurements of the Earth's gravity field. The GRACE mission is now in its calibration/validation phase and first results of the gravity field solutions are imminent. We consider here the possibility of external validation using data from the superconducting gravimeters in the European sub-array of the Global Geodynamics Project (GGP) as 'ground truth' for comparison with GRACE. This is a pilot study in which we use 14 months of 1-hour data from the beginning of GGP (1 July 1997) to 30 August 1998, when the Potsdam instrument was relocated to South Africa. There are 7 stations clustered in west central Europe, and one station, Metsahovi in Finland. We remove local tides, polar motion, local and global air pressure, and instrument drift and then decimate to 6-hour samples. We see large variations in the time series of 5-10 $\mu$ gal between even some neighboring stations, but there are also common features that correlate well over the 427 -day period. The 8 stations are used to interpolate a minimum curvature (gridded) surface that extends over the geographical region. This surface shows time and spatial coherency at the level of 2$4 \mu \mathrm{gal}$ over the first half of the data and 1-2 $\mu$ gal over the latter half. The mean value of the surface clearly shows a rise in European gravity of about $3 \mu \mathrm{gal}$ over the first 150 days and a fairly constant value for the rest of the data. The accuracy of this mean is estimated at $1 \mu \mathrm{gal}$, which compares favorably with GRACE predictions for wavelengths of $500 \mathrm{~km}$ or less. Preliminary studies of hydrology loading over Western Europe shows the difficulty of correlating the local hydrology, which can be highly variable, with large-scale gravity variations.
\end{abstract}

Key words. GRACE, satellite gravity, superconducting gravimeter, GGP, ground truth

Correspondence to: D. Crossley (crossley@ eas.slu.edu)

\section{Introduction}

The stimulus for this study originated with Wahr et al. (1998) who discussed the expected accuracy of surface gravity fluctuations for the proposed GRACE mission. They demonstrated that a careful accounting for the various contributions to time varying gravity would permit the determination of small time-varying signals such as variations in continental water storage. It was immediately clear that we should consider the possibility of combining satellite data and ground-based data from the Global Geodynamics Project (GGP; Crossley et al., 1999). The GGP superconducting gravimeter (SG) network is far too sparse geographically to be suitable as a global gravity field, but there are sub-arrays of instruments, particularly in Asia and Europe, that warrant closer consideration. Preliminary attempts at producing a ground-based map of gravity variations were reported by Crossley and Hinderer (1999) and later by Crossley and Hinderer (2002).

Recently, Velicogna and Wahr (2001) suggested that ground based gravity measurements cannot usefully contribute to the validation or analysis of GRACE data. They argue that the radius over which a single ground-based measurement extends (several 10's km) is incompatible with the wavelengths of satellite-derived fields $(>200 \mathrm{~km})$. Second, using GGP data from the International Centre for Earth Tides, they used statistical arguments to argue against any correlation of the signals over long time spans. The wavelength argument is true for a single station but the limitation can be overcome, to some extent, by the use of a gravity array. The question of the treatment of GGP data can only be answered by taking care in the analysis to preserve longterm integrity of each data set. Here we address both issues by processing the GGP data for a specific epoch, finding that the correlation between gravity variations over distances of several hundred $\mathrm{km}$ and time spans of several months is quite convincing. 
Table 1. European GGP stations used in the analysis

\begin{tabular}{lccccc}
\hline Station & Code & Country & Instrument & Latitude & Longitude \\
\hline Brussels & BE & Belgium & T003 & 50.7986 & 4.3581 \\
Membach & MB & Belgium & C021 & 50.6093 & 6.0066 \\
Medicina & MC & Italy & C023 & 44.5219 & 24.3958 \\
Metsahovi & ME & Finland & T020 & 60.2172 & 24.3958 \\
Potsdam & PO & Germany & T018 & 52.3806 & 13.0682 \\
Strasbourg & ST & France & C026 & 48.6217 & 7.6838 \\
Vienna & VI & Austria & C025 & 48.2493 & 16.3579 \\
Wettzell & WE & Germany & SG103 & 49.1440 & 12.8780 \\
\hline
\end{tabular}

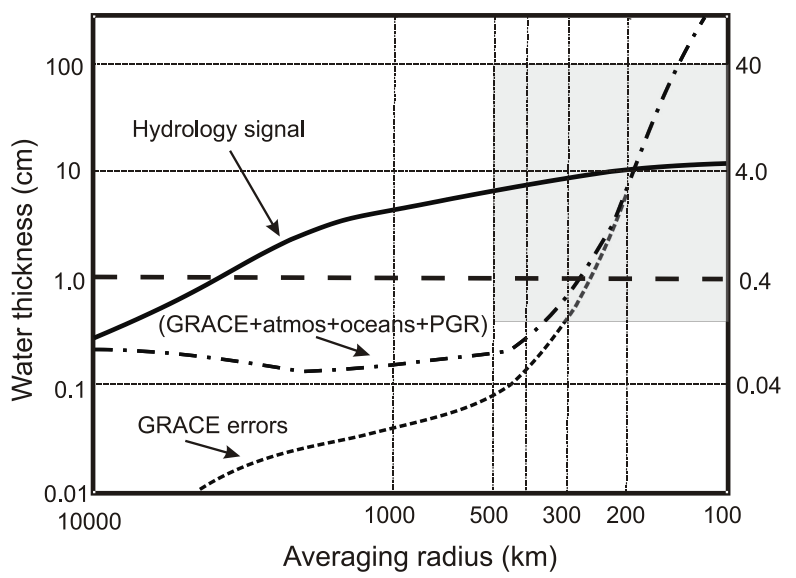

Fig. 1. Hydrology recovery from GRACE.

\section{GRACE goals}

GRACE (Gravity Recovery and Climate Experiment) is a joint venture of NASA (USA), DLR (Germany), UTCSR (Texas), and GFZ (Potsdam). The mission has now been actively collecting data for about 9 months and the first results are to be reported soon (AGU Abstracts, Fall Meeting 2002). The high accuracy anticipated of GRACE data should enable subtle time variations in the gravity field to be found, i.e. changes in continental water storage, the variability of ocean bottom pressure, and the redistribution of snow and ice. These changes will be determined by successive spherical harmonic solutions of the data with a limiting ground resolution of $100-200 \mathrm{~km}$ and intervals of 2-4 weeks.

The methodology follows the sequence (Wahr et al., 1998):

- assume a density change $\Delta \rho$ in a layer of thickness $H$ $(10-15 \mathrm{~km})$ surrounding the Earth's surface (i.e. the lower atmosphere and upper hydrosphere).

- convert $\Delta \rho$ to a surface density distribution $\Delta \sigma$ by integrating over $H$.

- expand $\Delta \sigma$ in spherical harmonics, with coefficients $\left(\hat{C}_{l}^{m}, \hat{S}_{l}^{m}\right)$

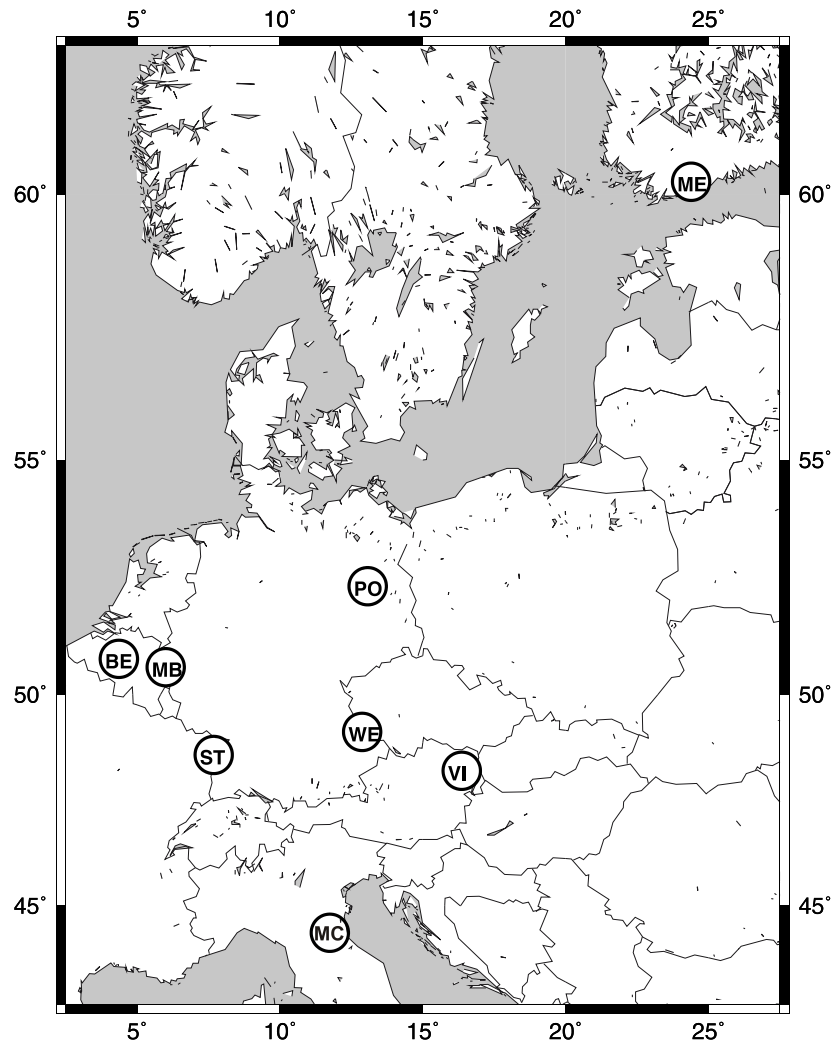

Fig. 2. GGP stations July 1997 - August 1998.

- relate these harmonics to the harmonics $\left(\hat{C}_{l}^{m}, \hat{S}_{l}^{m}\right)$ of the gravity field, determined from the GRACE satellite orbit data, approximately every 14 days.

- deduce $\Delta \sigma$ from $\left(\hat{C}_{l}^{m}, \hat{S}_{l}^{m}\right)$, and thus infer $\Delta \rho$ by assuming $H$.

Note that $\Delta \sigma$ does not distinguish between water, ice, or snow. It is also evident that the GRACE data will be timealiased if there is any unmodeled variation of gravity on time scales less than 2 weeks, as seems probable for the atmosphere and oceans (e.g. Flechtner et al., 2002).

One of the examples considered by Wahr et al. (1998) is for Manaus, Brazil, in the Amazon River Basin (Fig. 1). The upper curve shows the predicted hydrology signal, the middle curve is the expected errors in GRACE data with all sources of modeling (PGR is post glacial rebound), and the lower trace is for GRACE errors alone. The accuracy of the recovery using the full 5 years of data is $2 \mathrm{~mm}$ of water at length scales longer than $400 \mathrm{~km}$; a more recent estimate indicates better than $1 \mathrm{~cm}$ at $200 \mathrm{~km}$ or longer (Swenson et al., 2002). The errors at shorter wavelengths rise rapidly, becoming excessive at wavelengths less than $200 \mathrm{~km}$. The shaded box is the region where GRACE errors and GGP network errors are expected to overlap. To be competitive, ground-based gravity measurements need (a) to cover wavelengths between 100 and $1000 \mathrm{~km}$ and (b) to reach accuracies of less than $0.4 \mu \mathrm{gal}$ at wavelengths between 200 and $300 \mathrm{~km}$. If both conditions are satisfied, we may claim that ground-based (in 


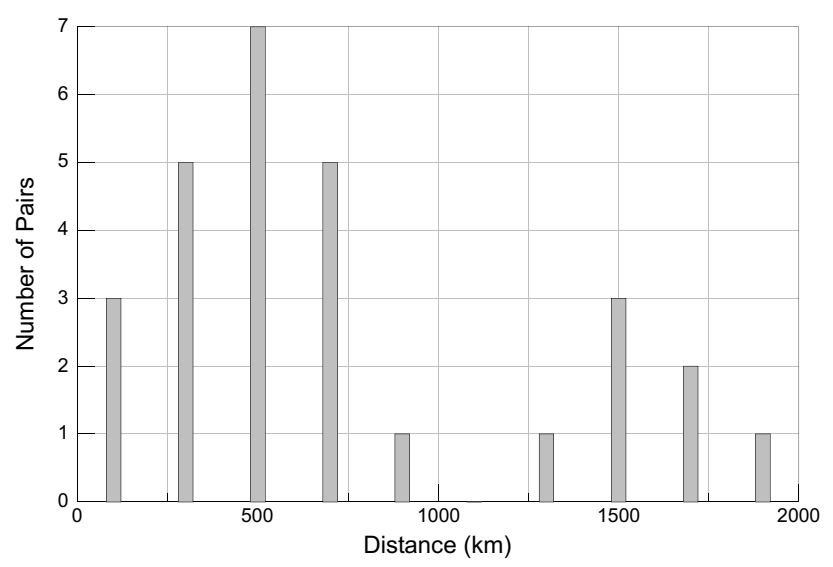

Fig. 3. Station distribution by pairs.

this case GGP) gravity can be used to 'validate' satellite measurements.

\section{GGP data}

The stations used in this study are shown in Table 1 and Fig. 2. All stations except ME are in the middle of the Western European landmass. The time period of this analysis was chosen to begin at the start of GGP (97/7/1) and continue to the end of the recording at PO $(98 / 8 / 31)$. The PO SG was then reconstructed as a dual sphere instrument and moved to South Africa (Neumeyer et al., 2001). Station MC is not officially a GGP station, but data are available for this study through the work of Zerbini et al. (2001). Station BE stopped recording in 2000 and the instrument at Wettzell, which was a prototype compact dewar model (designation SG103) with unusually large drift (Harnisch et al., 2000), has been replaced with a new dual sphere model. Also a new station, Moxa, was started in 2000 (Kroner et al., 2001). The distribution, or spacing, of the 8 stations taken in pairs, is plotted as a histogram in Fig. 3. The distance range of $200-1000 \mathrm{~km}$ is well covered, but the inclusion of a single distant station (ME) extends the coverage up to $2000 \mathrm{~km}$.

\section{Processing}

The first step is to remove a modeled tide from each station using local tidal gravimetric factors $(\delta, \kappa)$ obtained from independent analyses of data from each station. We include all waves with periods up to a month. For semi-annual and longer periods we use nominal elastic gravimetric values of $(1.16,0)$ to avoid fitting artificially the residual annual signals. We also remove the effect of local atmospheric pressure using a nominal admittance of $-0.3 \mu \mathrm{gal} \mathrm{mbar}^{-1}$; using slightly different values will not be a major source of error in the final result. The residual series are displayed in Fig. 4. It is clear station WE has a large negative drift that appears

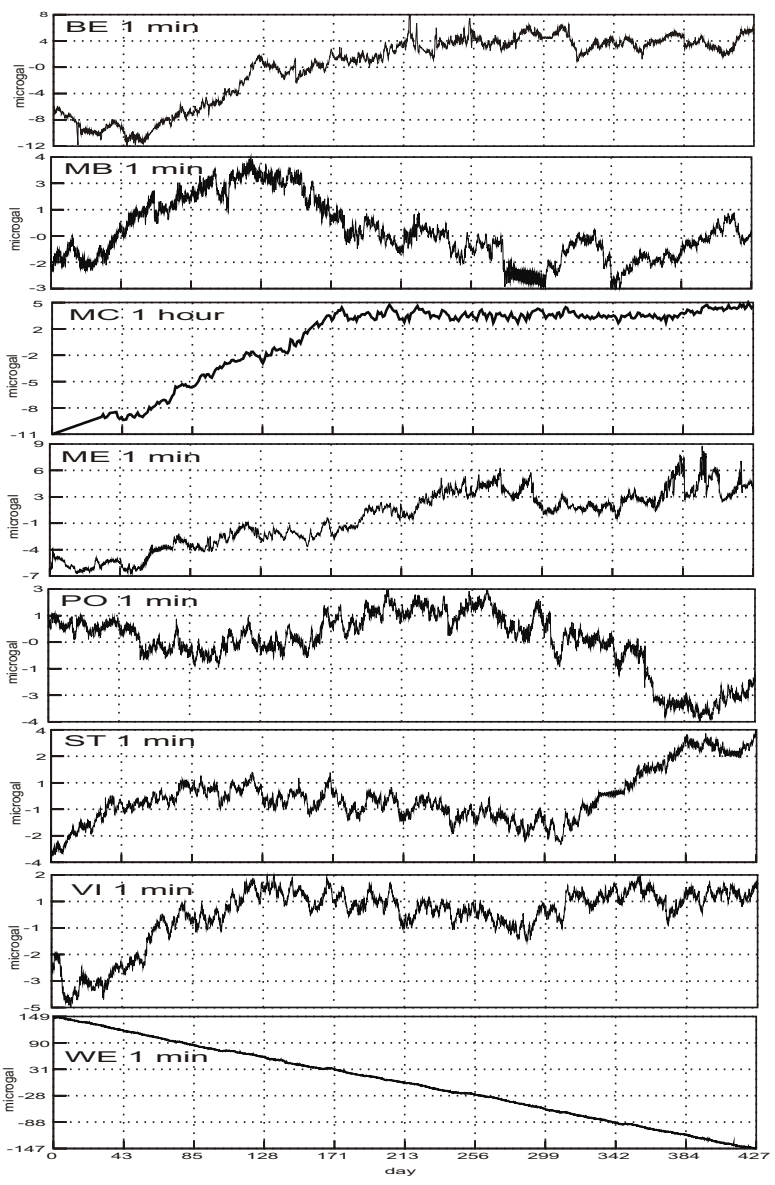

Fig. 4. Gravity residuals after removal of tides, local pressure and polar motion. Note the different scales of each data set.

linear. IERS-derived polar motion was also subtracted from each data set.

\section{Instrument drift}

For WE, we fit simultaneously a linear drift function and a series of offsets (already corrected in Fig. 4) at fixed time locations; this is done iteratively to arrive at an appropriate correcting function. In Fig. 5 the residuals are now plotted on a common axis, with the drift of station WE removed. We now remove the instrument drift at the other stations. Rather than do the analysis solely on the basis of the 14 months of data at our disposal, we requested assistance from the station operators who have analyzed their data over much longer time periods. The results are shown in Table 2. It is seen that apart from WE (discussed above), most of the stations have drift rates in the $1-4 \mu \mathrm{gal} \mathrm{yr}^{-1}$ range. The most reliable estimates come from comparisons with Absolute Gravimeter data, but at some stations this was not possible. At one station (MC), the data were further checked using a series of GPS measurements (Zerbini et al., 2001) to establish vertical motion. The drift of station MB is a high compared to the other stations, 
Table 2. Drift functions removed for each station

\begin{tabular}{clcll}
\hline Station & Author & Drift $(\mu \mathrm{gal} / \mathrm{yr})$ & Function & Method \\
\hline BE & B. Ducarme & 0.0 & exponential & Estimated from last disturbance \\
MB & M. van Camp et al. & 4.90 & linear & Comparison with AG \\
MC & B. Richter & 2.50 & exponential & Comparison with AG and GPS \\
ME & H. Virtanen & 3.75 & linear & Comparison with AG \\
PO & J. Neumeyer & 1.64 & linear & Fit to long series \\
ST & J. Hinderer et al. & 3.65 & linear & Comparison with AG \\
VI & B. Meurers & 2.25 & linear & Fit to long series \\
WE & G. and M. Harnisch & -253.95 & linear & Fit to series \\
\hline
\end{tabular}

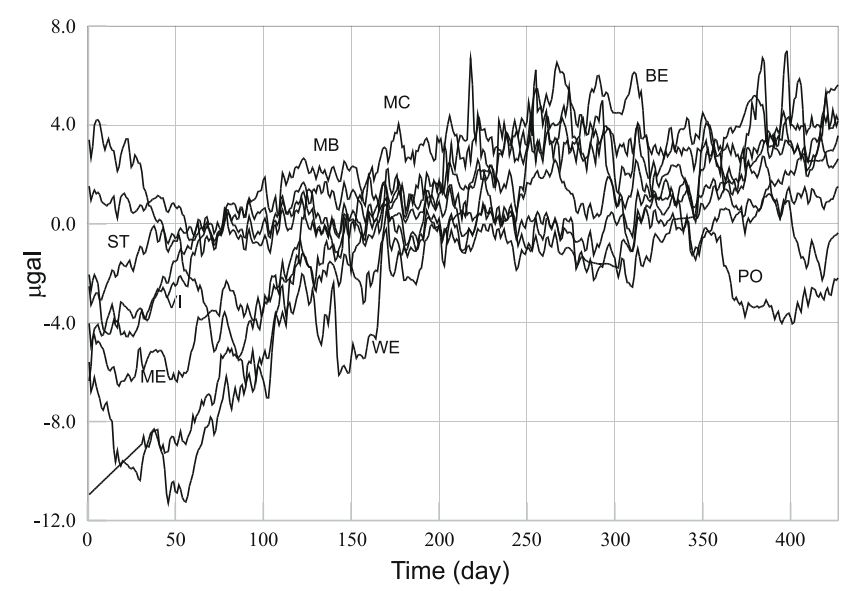

Fig. 5. Gravity residuals, 1 hour, mean values removed.

but it has been carefully checked and has found to be reliable (van Camp et al., 2002).

\section{Global pressure loading}

We now correct for the non-local atmospheric pressure effects, first decimating the data further to 6-hour samples. The global atmospheric loading has been calculated by Jean Paul Boy (personal communication) using the method described in Boy et al. (2001). The assumption is that the vertical column is hydrostatic and so the mass attraction and loading are dependent only on the surface pressure, here obtained from the ECMWF.

The results for the 8 stations are shown in Fig. 6 as the difference between local and global loading. The differences between global and local corrections are significant $(-1.5$ to $+2 \mu \mathrm{gal})$ over short periods, but there is little or no long term trend. More importantly, all stations respond in a similar fashion, indicating that the global loading is intergrating over atmospheric masses of the same size or larger than this station distribution.

To illustrate the effect of the global loading on the gravity residuals, we show the results for $\mathrm{ME}$, where the differences are the largest (Fig. 7, in which the dashed line is the

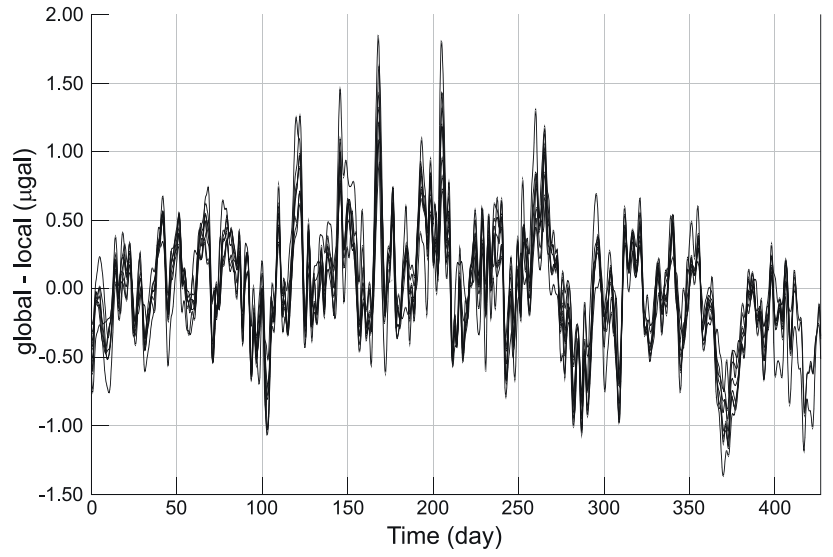

Fig. 6. Global vs local atmospheric pressure loading.

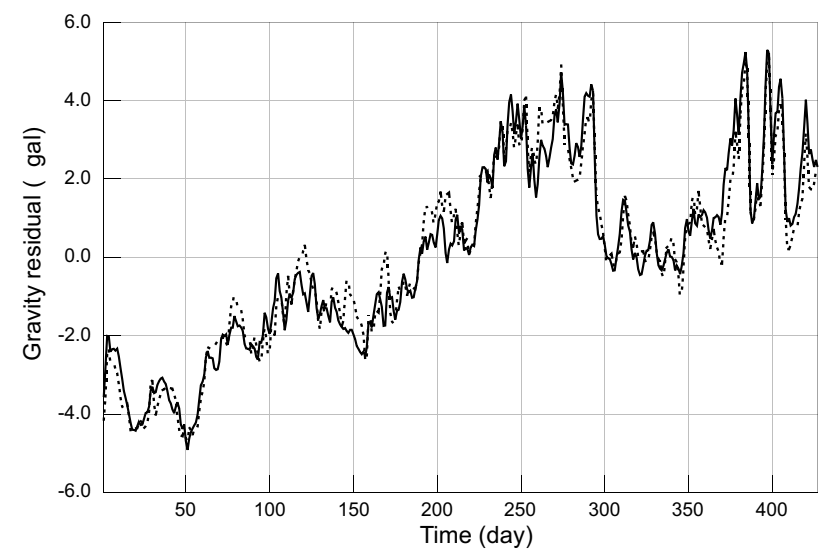

Fig. 7. Effect of global pressure loading at station ME.

local correction). Clearly the inclusion of global pressure does not significantly affect the trend of the gravity residuals. This type of computation has since been updated (Boy and Chao, 2002) by using a three-dimensional atmospheric model and they find that seasonal changes due to global loading are more significant than those shown here. Their method will be incorporated in future work on this project.

Figure 8 shows the final residual gravity, corrected for the 


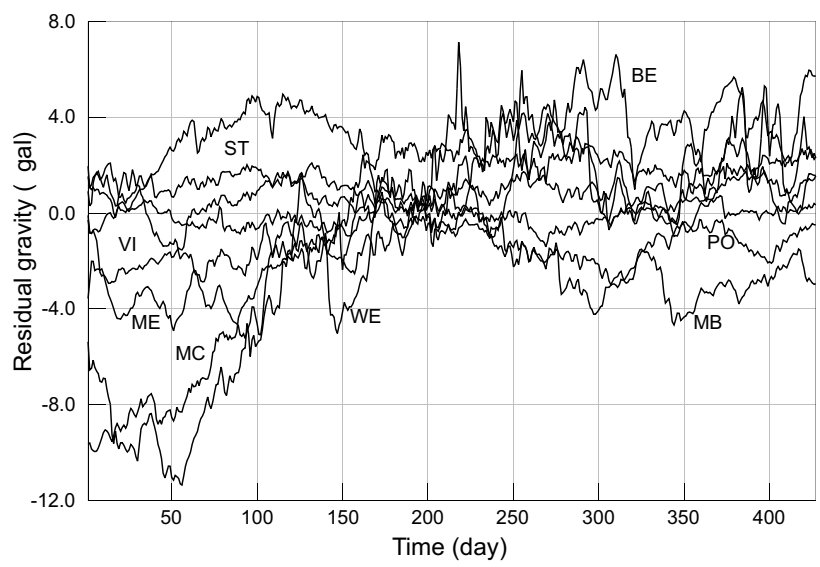

Fig. 8. Final residual gravity after all corrections.

drift in Table 2 and the atmospheric loading in Fig. 6. It can be seen the the series are somewhat flatter than Fig. 5, but still with a significant spread of values, especially during the first 150 days.

\section{Spatial averaging}

We need to consider how to spatially average the individual station residuals to simulate the integrating effect of the satellite measurements. To estimate the spherical harmonic coefficients of a global model from such a limited amount of ground data would definitely yield poor coefficients, so we proceed differently.

We first of all fit a minimum curvature surface to the data points on which Fig. 8 is derived. This fit is performed for each 6-hour sample of the field, and one of the properties of the surface is that it goes through each of the original points. This is therefore a good interpolation procedure and we can produce contour maps of the surface as a function of time. These maps do not do any spatial averaging of the field and neighboring stations with conflicting series (e.g. BE and MB) still show up as inconsistencies (we cannot shows these maps here due to lack of space). As a second step we therefore fit a polynomial surface to the data using the whole of this interpolated surface (not just the original data points), in order to get a robust least squares solution. We choose a third degree polynomial because this gives a reasonable smoothing about a wavelength of $500 \mathrm{~km}$. Higher order polynomials may also be justified, but we have not investigated all possibilities. The resulting surface is then re-sampled at each of the original station locations and a set of smoothed time series is produced (Fig. 9). The series now show much less deviation and the data that stands out from the rest is ME, due partly to its distance from the other stations and the poor control due to the lack of neighboring stations.

We now re-sample the residuals to 14 days to represent satellite repeat determinations of the field, to produce the series in Fig. 10. We claim that this figure represents our inter-

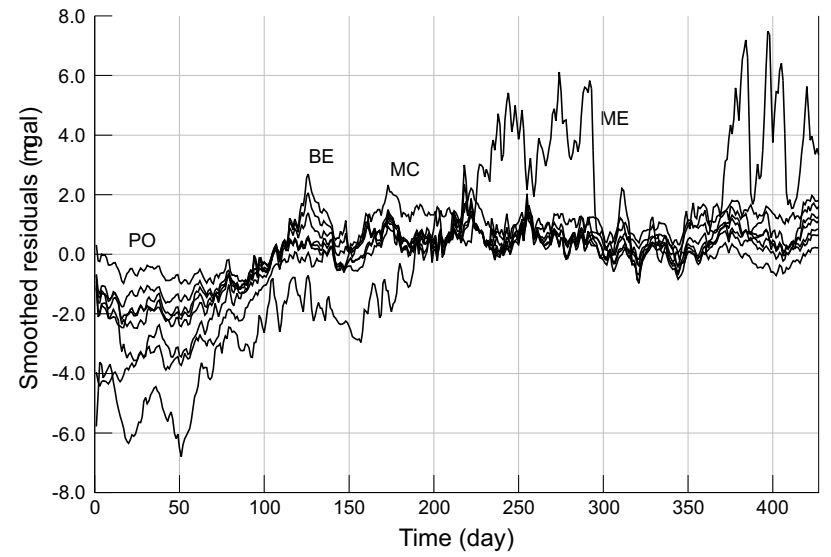

Fig. 9. Spatially smoothed residuals, 6-hour sampling.

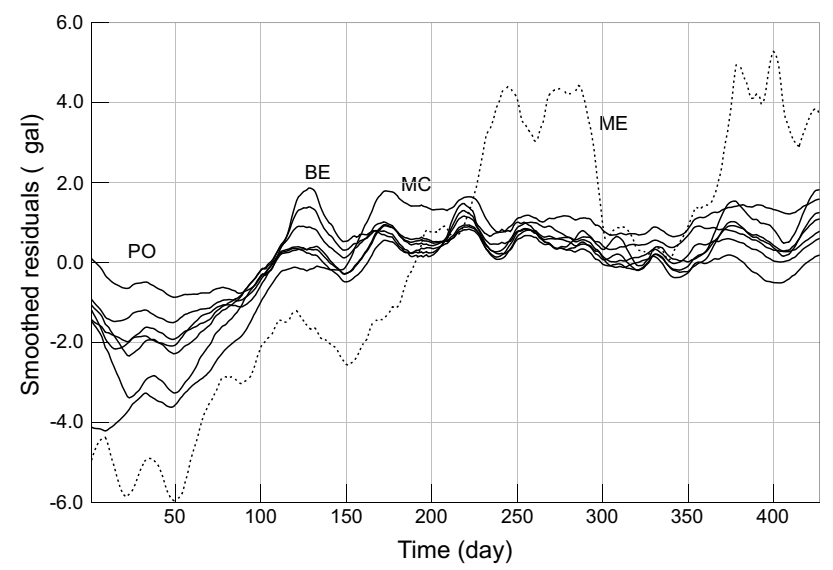

Fig. 10. Spatially smoothed residuals, 14-day sampling.

pretation of a time and space averaged picture of the gravity field. It is difficult to place error estimates on these series due to the various processing steps involved, but one further step might be to average all the series together (except ME since this is an outlying station) and compute the errors in this final average. This is done in Fig. 11, which is our final result. It shows that the $1 \sigma$ errors are of the order of $1-2 \mu$ gal for the first 150 days, and less than $1 \mu \mathrm{gal}$ for the reset of the time period.

\section{Hydrology}

So far we have made no allowance for hydrology, either large scale or local, because in fact this signal will also be seen by the satellite. The variability of continental water storage is a prime target for GRACE and clearly one that affects surface gravity measurements. Van Dam et al. (2001) showed that at the GGP stations their models predict large variations of water-induced gravity changes that are frequently dominated by annual variations of the order of $10 \mu \mathrm{gal}$. Such effects are 


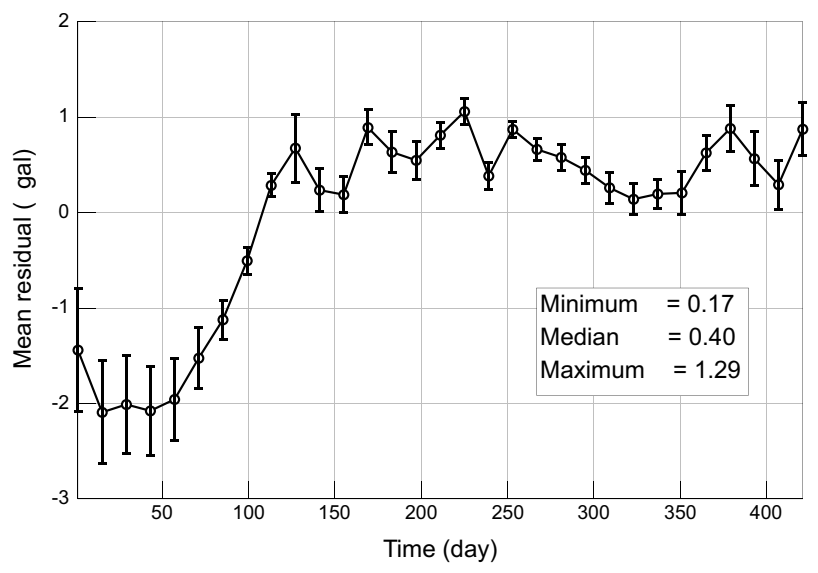

Fig. 11. Evolution of the mean field, ME omitted.

difficult to separate from other possible annual signals in the residuals, e.g. global pressure effects.

At the same time the analysis of local hydrology is often usefully done to remove a water signal in gravity recordings, e.g. Crossley et al. (1998), Kroner (2001), and Virtanen (2001). Frequently there is a high correlation between local measures, such as rainfall and water table depth, and residual gravity and this correlation is used to justify the modeling. One source of uncertainty is the interpretation of the resulting admittance, as this depends on the local porosity. Frequently the empirical estimate of porosity obtained from the admittance is difficult to verify on physical grounds.

A long-term project has been initiated to estimate continental water storage in central Europe. We (Florsch and Llubes, 2002) have performed loading estimates of largescale $(2000 \times 3000 \mathrm{~km})$ hydrology over Europe by placing a $1 \mathrm{~m}$ water load on the continental crust. The vertical crustal displacement reaches a maximum of $4.6 \mathrm{~cm}$ at the center of the load and less than $1.0 \mathrm{~cm}$ outside the area. This gives a central effect of $14 \mu \mathrm{gal}$ in gravity to which must be added about $42 \mu \mathrm{gal}$ in direct Newtonian attraction; the total effect is therefore $0.56 \mu \mathrm{gal}$ per $\mathrm{cm}$ water (at $100 \%$ porosity). At a smaller scale we have simulated a loading of $1 \mathrm{~m}$ water over the Alsace region of the lower Rhine Graben (about $20 \times 300 \mathrm{~km}$ ) and find a very localized loading effect of $1.6 \mu \mathrm{gal}$, with again the dominating direct effect of $42 \mu \mathrm{gal}$, thus a total of $0.44 \mu \mathrm{gal}$ per $\mathrm{cm}$ water.

As is widely recognized, hydrology can be extremely complex at regional scales. A good example can be found at the website (http://aesn.brgm.fr/bulletin/nappes. html) run by l'Agence de L'Eau Seine-Normandie, in which the water table has been monitored at over 60 sites over the Seine Basin since 1975. The correlation between neighboring sites is often poor because of the geological variability, (http://aesn.brgm.fr/bulletin13/images/situation nappe.gif), whereas some sites are well correlated even at relatively large distances. Determining the true hydrological signal will inevitably require a combination of direct water table measurements and gravity observations, the latter in- cluding both ground-based and satellite data.

\section{Discussion and conclusions}

One may, with some justification, question the somewhat adhoc procedure used to get from the gravity residuals (Fig. 8) to the smoothed integrated curve of the gravity field evolution (Figs. 9 to 11). At the present time we are considering alternative ways of doing this. Nevertheless, it is evident that even in Fig. 8. there is spatial and temporal coherency of the field over the 427 days, and this becomes more obvious in the smoothed product, Figs. 9 and 10. Station ME is unusual in more than its geographic isolation from the other stations. As Virtanen et al. (2002) have shown, the loading effects of the Baltic Sea are quite strong and account for much of the variability seen in Fig. 10. So far this loading has not been corrected in the current study, but it will be seen by a satellite, so one has to be careful to compare fields that have been consistently processed.

Further work is being done to extend these series to more recent years, in particular into 2000 when the CHAMP satellite started to produce results. It is difficult to produce a gravity surface in real time from GGP data due to the care needed in processing and the need to make systematic absolute gravity measurements to check the drift. Nevertheless the GGP data certainly enables such maps of the evolution of the European gravity field to be made. A longer-term goal might be to establish further SGs in the missing regions (e.g. Spain, Poland, Northern Germany) that would undoubtedly significantly improve the quality of the gravity field estimation. In future we believe this work will provide a useful source of data with which GRACE and other satellite missions may be compared.

Acknowledgements. We thank the various European SG station operators (Table 2) for making the data available through GGP. This research was supported by CNRS; it is EOST contribution No. 2002-16-7516.

\section{References}

Boy, J.-P., Gegout, P., and Hinderer, J.: Reduction of surface gravity data from global atmospheric loading, Geophys. J. Int., 149, 534-545, 2000.

Boy, J.-P. and Chao, B. F.: Effects of the vertical structure of the atmosphere on gravity at satellite altitude, Geophys. Res. Abs., EGS 27 General Assembly, 4, EGS02-A-03837, 2002.

Crossley D., $\mathrm{Xu}, \mathrm{S}$., and van Dam, T.: Comprehensive analysis of 2 years of data from Table Mountain, Colorado, Proc. 13th Int. Symp. Earth Tides, Brussels, July 1997, Royal Observatory of Brussels, 659-668, 1998.

Crossley, D. J. and Hinderer, J.: Global gravity campaigns - from the ground (GGP) to the sky (GRACE), IUGG XXII General Assembly, Abstract Volume A, 71-72, 1999.

Crossley, D. J., Hinderer, J., Casula, G., Francis, O., Hsu, H.-T., Imanishi, Y., Meurers, B., Neumeyer, J., Richter, B., Shibuya, K., Sato, T., and van Dam, T.: Network of superconducting gravimeters benefits several disciplines, EOS, 80, 121-126, 1999. 
Crossley, D. and Hinderer, J.: GGP Ground Truth for Satellite Gravity Missions, Bull. D’Inf. Marees Terr., 136, 10735-10 742, 2002.

Flechtner, F., Zlotnicki, V., and Pekker, T.: Atmospheric and oceanic gravity field de-aliasing for GRACE, Geophys. Res. Abs., EGS 27 General Assembly, 4, EGS02-A-01557, 2002.

Florsch, N. and Llubes, M.: Geodetic impact of acquifer on regional gravity survey, Geophys. Res. Abs., EGS 27 General Assembly, 4, EGS02-A-05536, 2002.

Harnish, M., Harnisch, G., Jurczyk, H., and Wilmes, H.: 889 days of registrations with the superconducting gravimeter SG103 at Wettzell (Germany), Cahiers du Centre Europeean de Geodynamique et de Seismologie, 17, 25-37, 2000.

Kroner, C.: Hydrological effects on Gravity at the Geodynamic Observatory, Moxa. J. Geod. Soc Japan, 47 (1), 353-358, 2001. Kroner, C., Jahr, T., and Jentzsch, G.: Comparison of Data Sets Recorded with the Dual Sphere SuperconductingGravimeter CD 034 at the Geodynamic Observatory, Moxa. J. Geod. Soc Japan, 47 (1), 398-403, 2001.

Neumeyer, J., Brinton, E., Fourie, P., Dittfeld, H.-J., Pflug, H., and Ritschel, B.: Installation and First Data Analysis of the Dual Sphere Superconducting Gravimeter at the South African Geodynamic Observatory, Sutherland, J. Geod. Soc. Japan, 47 (1), 316-321, 2001.

Swenson, S., Wahr, J., and Milly, P. C. D.: Large-scale hydrology inferred from GRACE estimates of time-variable gravity, Geo- phys. Res. Abs., EGS 27 General Assembly, 4, EGS02-A-03671, 2002.

Van Camp, M., Warnant, R., and Francis, O.: Crustal deformations in Membach, Belgium, Geophys. Res. Abs., EGS 27 General Assembly, 4, EGS02-A-00860, 2002.

Van Dam, T., Wahr, J. M., Milly, P. C. D., and Francis, O.: Gravity changes due to continental water storage, J. Geod. Soc. Japan, 47 (1), 249-254, 2001

Velicogna, I. and Wahr, J.: Potential problems with the use of gravimeter data for GRACE Cal/Val., EOS Trans. AGU, 82 (47), Fall Meet. Suppl., Abstract G51A-0242, 2001.

Virtanen, H.: Hydrological studies at the Gravity Station Metsahovi in Finland, J. Geod. Soc. Japan, 47 (1), 328-333, 2001.

Virtanen, H., Makinen, J., Bilker, M., Poutanen, M., Haarala, S., and Kahma, K.: Loading effects from the Baltic Sea and atmosphere in Metsahovi, Finland, Geophys. Res. Abs., EGS 27 General Assembly, 4, EGS02-A-04342, 2002.

Wahr, J., Molenaar, M., and Bryan, F.: Time variability of the Earth's gravity field: hydrological and oceanic effects and their possible detection using GRACE, J. Geophys. Res., 103 (B12), 30 205-30 229, 1998.

Zerbini, S., Richter, B., Negusini, M., Romagnoli, C., Simon, D., Domenichina, F., and Schwahn, W.: Height and gravity various by continuous GPS, gravity and environmental parameter observations in the southern Po Plain, near Bologna, Italy, Earth Planet. Sci. Lett., 192, 267-279, 2001. 